Research Paper

\title{
Clinical validation of Ki67 by quantitative reverse transcription-polymerase chain reaction (RT-PCR) in HR+/HER2- early breast cancer
}

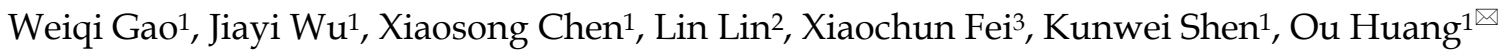 \\ 1. Comprehensive Breast Health Center, Ruijin Hospital, Shanghai Jiaotong University School of Medicine, Shanghai 200025, China \\ 2. Department of clinical laboratory, Ruijin Hospital, Shanghai Jiaotong University School of Medicine, Shanghai 200025, China \\ 3. Department of pathology, Ruijin Hospital, Shanghai Jiaotong University School of Medicine, Shanghai 200025, China. \\ $\square$ Corresponding author: Ou Huang, Email: ou_huang@126.com, Telephone number: +86 13761163869, Fax number: +86 02164156886 \\ (c) Ivyspring International Publisher. This is an open access article distributed under the terms of the Creative Commons Attribution (CC BY-NC) license \\ (https://creativecommons.org/licenses/by-nc/4.0/). See http://ivyspring.com/terms for full terms and conditions.
}

Received: 2018.08.18; Accepted: 2018.12.18; Published: 2019.01.29

\begin{abstract}
Objective: To evaluate the clinical value of Ki67 by RT-PCR, we investigated the concordance of $\mathrm{Ki} 67$ expression by IHC and by RT-PCR, and assessed their prognostic value in HR+/HER2- early breast cancer.

Methods: 1259 HR+/HER2- early breast cancer patients treated at Ruijin Hospital with recurrence score were retrospectively recruited. RT-PCR assay measurement of Ki67 was conducted by 21 -gene expression assay and compared with IHC measurement of $\mathrm{Ki} 67$ using chi-square tests. X-tile program was used to determine the optimal cutoff point for Ki67 by RT-PCR. Survival analyses were performed by Kaplan-Meier analysis and log-rank tests, and hazard ratios were derived from the Cox proportional hazards model.

Results: Ki67 by RT-PCR had a weak positive correlation with Ki67 by IHC. Pathology, grade and $\mathrm{Ki} 67$ expression by IHC were significantly related to the concordance between two assays, and most discordance cases were seen in patients with Ki67 ranging from 10 to 29. The estimated 3-year DFS was $96.0 \%$ in low, and $92.5 \%$ in high expression group of $\mathrm{Ki} 67$ by IHC, $97.0 \%$ in low and $90.4 \%$ in high expression group of $\mathrm{Ki} 67$ by RT-PCR. Univariate and multivariate analysis in the whole population indicated that only Ki67 by RT-PCR - but not intrinsic subtype or recurrence score - was an independent factor for DFS.

Conclusions: Ki67 assessed by RT-PCR assay was weakly correlated to Ki67 by IHC. Using 5.68 as cutoff point, Ki67 by RT-PCR had shown potential as a prognostic biomarker in HR+/HER2- early breast cancer.
\end{abstract}

Key words: Breast cancer, Ki67, 21-gene expression assay, Prognostic marker

\section{Introduction}

Ki67 as the most commonly used proliferation marker, was first detected in 1983 as a nuclear protein in Hodgkin's lymphoma cell line [1]. Its expression varies throughout the cell cycle. Ki67 is highly expressed in $\mathrm{M}$ phase of the cell cycle, but not in G0 phase [2]. In the era of individualized treatment, Ki67 evaluated by immunohistochemistry (IHC) is increasingly used to assess tumor proliferation, classify different tumor subtypes, predict benefit of different treatments, and help decide the use of adjuvant chemotherapy in conjunction with conventional prognostic markers for early breast cancer [3-6]. However, Ki67 is still controversy as a biomarker because of the inter-observer variability in the assessment and undefined optimal cut point as a continuous variable [7-10].

The 21-gene expression assay including 16 cancer-related genes and 5 reference genes, was 
developed as a multi-gene array to assess the residual risk after surgery in early breast cancer patients with HR-positive, HER2-negative and node-negative disease from three independent cohorts [11]. Recurrence score (RS) was significantly correlated with the incidence of breast cancer recurrence and the likelihood of patients' benefit from adjuvant chemotherapy [11-13]. The proliferation group in the 21-gene expression assay consists of Ki67, STK15, Survivin, CCNB1 and MYBL2. The expression of Ki67 as well as the other genes in this setting is based on quantitative reverse-transcriptase polymerase chain reaction (RT-PCR) using RNA extracted from formalin-fixed and paraffin-embedded tissue (FFPE), which might be the potential solution to problems of inter-observer variability and analytical subjectivity in Ki67 scoring.

The aim of the present analysis was to retrospectively assess the value of RT-PCR as an objective alternative to IHC for Ki67 scoring. We assessed the correlation between the proliferation group in the 21-gene expression assay and Ki67 by IHC, analyzed the impact of clinic-pathological factors on the concordance, and evaluated the prognostic value of RT-PCR assessment of Ki67 in 1259 HR+/HER2- early breast cancer patients.

\section{Materials and Methods}

\section{Patients}

Patients aged $\geq 18$ years with histologically proven operable invasive breast cancer treated in Ruijin Hospital were retrospectively reviewed in this study. Further inclusion criteria included HR-positive, HER2-negative disease, and 0-3 lymph nodes involved. Patients had undergone either mastectomy or breast conserving surgery with subsequent radiotherapy. Either a negative sentinel-node biopsy or axillary dissection was required. RS by 21-gene RT-PCR assay was also required for the recruited patients. Main exclusion criteria included advanced breast cancer, previous or concurrent malignant disease and neo-adjuvant systemic therapy for breast cancer.

The current study has received approval from the independent ethics committee of Ruijin Hospital. All patients provided written informed consent.

\section{Immunohistochemistry and FISH}

IHC measurement of all samples was independently performed by two pathologists. In the pathology laboratory of Ruijin Hospital, ER and PR status were evaluated on FFPE tissue blocks by IHC using the ER/PR PharmDX kit. Tumors were classified as ER- or PR-positive when $\geq 1 \%$ invasive tumor cells showed definite nuclear staining, irrespective of staining intensity [14]. HER2 expression was assessed with the HercepTest kit and scored as $0,1+, 2+$, or $3+$, according to American Society of Clinical Oncology (ASCO)/CAP guidelines [15]. Tumors scored as 2+ were retested with fluorescence in situ hybridization (FISH) using the PathVysion HER2 DNA probe kit. Cases were considered HER2-positive if scored 3+ by IHC and/or amplified by FISH (HER2/CEP17 ratio $\geq 2$ or average HER2 copy number $\geq 6.0$ signals/cell) [15].

IHC measurement of Ki67 was visually scored on FFPE tissue blocks concurrently with ER and PR by two pathologists. IHC for Ki67 used the MIB-1 clone. According to the recommendations from International Ki67 in Breast Cancer Working Group, Ki67 index was defined as the percentage of tumor cell nuclear with positive immunostaining from at least three high-power $(\times 40$ objective) fields. And if there are clear hot spots, data from these would also be included in the overall score [16].

\section{Gene Expression Analysis Using 21-gene expression assay}

Three 10- $\mu \mathrm{m}$ sections of macro-dissected FFPE tumor samples were required for each patient used for RT-PCR assay. The expression of 16 cancer-related genes, including Ki67 and other proliferation related gene, were normalized relative to five reference genes (ACTB, GAPDH, GUSB, RPLP and TFRC)[11].

\section{Statistical analysis}

All statistical analyses were carried out in SPSS version 18.0. Correlation of continuous RT-PCR assay measurement of proliferation genes with IHC measurement of Ki67 was determined using Pearson correlation. Agreement of Ki67 expression status by IHC and by RT-PCR was examined by use of Cohen's $\mathrm{K}$ statistics and chi-square tests. The effects of the clinic-pathological variables on agreement of Ki67 status determined by two assays and differences of basic characteristics between training and validation cohorts were examined by use of chi-square tests. The optimal cutoff point for Ki67 by RT-PCR against DFS was determined using X-tile bioinformatics software version 3.6.1 [17-19]. Basic $R$ function sample() was used to divide the study cohort randomly into two cohorts to verify the results.

The standardized definitions for efficacy end points (STEEP) criteria was applied for the endpoint definition [20]. The primary endpoint of this trial was the rate of disease-free survival (DFS), defined as the first event of recurrence of ipsilateral breast tumor, local recurrence, regional recurrence, distant recurrence, contralateral second primary cancer, second primary non-breast invasive cancer, or death 
without evidence of recurrence. Disease-free survival rate was estimated using Kaplan-Meier estimator and tested with log-rank tests. To evaluate the prognostic value of Ki67 by RT-PCR and classical clinicopathological factors, univariate and multivariate (forward elimination) Cox proportional hazard models for DFS were estimated with each signature tested as a categorical variable. All measurements were associated with 95\% confidence intervals $(95 \% \mathrm{CI})$. Statistical tests were considered significant for $\mathrm{P}<0.05$.

Table 1. Distributions of Patient and Tumor Characteristics in all patients, and in training and validation cohorts

\begin{tabular}{|c|c|c|c|c|}
\hline \multirow[t]{2}{*}{ Characteristics } & \multirow[t]{2}{*}{ All patients } & \multicolumn{3}{|l|}{ X-tile program } \\
\hline & & Training cohort & $\begin{array}{l}\text { Validation } \\
\text { cohort }\end{array}$ & $\begin{array}{l}\mathrm{p} \\
\text { value }\end{array}$ \\
\hline $\begin{array}{l}\text { Age, median (range), } \\
\text { years }\end{array}$ & $57(24-93)$ & $57(24-92)$ & $56(29-93)$ & \\
\hline Pathology, No. (\%) & & & & 0.58 \\
\hline IDC & $1092(86.7 \%)$ & $544(86.5 \%)$ & $548(87.0 \%)$ & \\
\hline ILC & $53(4.2 \%)$ & $30(4.8 \%)$ & $23(3.7 \%)$ & \\
\hline Others & $114(9.1 \%)$ & $55(8.7 \%)$ & $59(9.3 \%)$ & \\
\hline Tumor Size, No. (\%) & & & & 0.29 \\
\hline pT1 & $850(67.5 \%)$ & $427(67.9 \%)$ & $423(67.1 \%)$ & \\
\hline pT2-3 & $367(29.2 \%)$ & $186(29.6 \%)$ & $181(28.7 \%)$ & \\
\hline pTx & $42(3.3 \%)$ & $16(2.5 \%)$ & $26(4.2 \%)$ & \\
\hline Nodal status, No. (\%) & & & & 0.08 \\
\hline $\mathrm{pN} 0-\mathrm{mic}$ & $1091(86.6 \%)$ & $540(85.9 \%)$ & $551(87.5 \%)$ & \\
\hline $\mathrm{pN} 1$ & $161(12.8 \%)$ & $88(14.0 \%)$ & $73(11.6 \%)$ & \\
\hline $\mathrm{pNx}$ & $7(0.6 \%)$ & $1(0.1 \%)$ & $6(0.9 \%)$ & \\
\hline Grade, No. (\%) & & & & 0.89 \\
\hline G1-2 & $818(74.8 \%)$ & $410(75.0 \%)$ & $408(74.6 \%)$ & \\
\hline G3 & $276(25.2 \%)$ & $137(25.0 \%)$ & $139(25.4 \%)$ & \\
\hline ER expression, No. (\%) & & & & 0.21 \\
\hline$<50 \%$ & $119(9.5 \%)$ & $53(8.4 \%)$ & $66(10.5 \%)$ & \\
\hline$\geq 50 \%$ & $1140(90.5 \%)$ & $576(91.6 \%)$ & $564(89.5 \%)$ & \\
\hline PR expression, No. $(\%)$ & & & & 0.03 \\
\hline$<20 \%$ & $463(36.8 \%)$ & $213(33.9 \%)$ & $250(39.7 \%)$ & \\
\hline$\geq 20 \%$ & $796(63.2 \%)$ & $416(66.1 \%)$ & $380(60.3 \%)$ & \\
\hline Ki67 by IHC, No. (\%) & & & & 0.71 \\
\hline$\leq 14 \%$ & $658(52.3 \%)$ & $332(52.8 \%)$ & $326(51.7 \%)$ & \\
\hline$>14 \%$ & $601(47.7 \%)$ & $297(47.2 \%)$ & $304(48.3 \%)$ & \\
\hline $\begin{array}{l}\text { Ki67 by RT-PCR, No. } \\
(\%)\end{array}$ & & & & 0.98 \\
\hline$\leq 5.68$ & $811(64.4 \%)$ & $405(64.4 \%)$ & $406(64.4 \%)$ & \\
\hline$>5.68$ & $448(35.6 \%)$ & $224(35.6 \%)$ & $224(35.6 \%)$ & \\
\hline $\begin{array}{l}\text { Intrinsic subtype, No. } \\
(\%)\end{array}$ & & & & 0.62 \\
\hline Luminal A-like & $402(31.9 \%)$ & $205(32.6 \%)$ & $197(31.3 \%)$ & \\
\hline Luminal B-like & $857(68.1 \%)$ & $424(67.4 \%)$ & $433(68.7 \%)$ & \\
\hline Recurrence Score resul & No. $(\%)$ & & & 0.53 \\
\hline$<11$ & $101(8.0 \%)$ & $46(7.4 \%)$ & $55(8.7 \%)$ & \\
\hline $11-25$ & $607(48.2 \%)$ & $311(49.4 \%)$ & $296(47.0 \%)$ & \\
\hline$>26$ & $551(43.8 \%)$ & $272(43.2 \%)$ & $279(44.3 \%)$ & \\
\hline Adjuvant chemotherap & y, No. (\%) & & & 0.296 \\
\hline Received & $636(50.5 \%)$ & $309(49.1 \%)$ & $327(52.1 \%)$ & \\
\hline Not received & $621(49.3 \%)$ & $320(50.9 \%)$ & $301(47.9 \%)$ & \\
\hline
\end{tabular}

\section{Results}

\section{Baseline Characteristics}

Table 1 presents the distributions of patient and tumor characteristics. The median age was 57 years old, ranging from 24 to 93 . Of all the patients, $67.5 \%$ were classified as pT1 and $29.2 \%$ as pT2-3. $84.4 \%$ were classified as $\mathrm{pN} 0,2.2 \%$ as $\mathrm{pNmic}$ and $12.8 \%$ as $\mathrm{pN} 1$. ER expression by IHC was $\geq 50 \%$ in $90.5 \%$ tumors, while PR expression by IHC was $\geq 20 \%$ in $63.2 \%$ tumors. And Ki67 expression by IHC was no more than $14 \%$ in $52.3 \%$ tumors. RS was available for all the recruited patients; of these, $8.0 \%$ were classified as low-risk group (RS<11), $48.2 \%$ as intermediate-risk group ( $R S=11$ to 25 ), and $43.8 \%$ as high-risk group (RS>25). After the multidisciplinary discussion, chemotherapy was omitted in nearly half of the patients on the basis of clinic-pathological factors and RS.

\section{Correlation between IHC assessment of Ki67 and RT-PCR measurement of proliferation genes}

Measurement of proliferation genes by RT-PCR in the 21-gene expression assay, including Ki67, CCNB1, MYBL2, STK15, and SURV, was validated on the FFPE tissue blocks of all the 1259 patients. Proliferation markers by RT-PCR had a weak positive Spearman correlation with Ki67 by IHC. Pearson correlation between Ki67 by RT-PCR assay and Ki67 by IHC was $0.345, \mathrm{p}<0.001 ; 0.081$ for CCNB1 by RT-PCR assay and Ki67 by IHC, p<0.001; 0.104 for MYBL2 by RT-PCR assay and Ki67 by IHC, p<0.001; 0.182 for STK15 by RT-PCR assay and Ki67 by IHC, $\mathrm{p}<0.001 ; 0.057$ for SURV by RT-PCR assay and Ki67 by IHC, $\mathrm{p}<0.001$ (Table 2).

Table 2. Pearson Correlation between $\mathrm{Ki} 67$ by $\mathrm{IHC}$ and Proliferation Genes in 21-gene Expression Assay

\begin{tabular}{lllllll}
\hline & Ki67 by IHC & Ki67 by PCR & CCNB1 & MYBL2 & STK15 & SURV \\
\hline Ki67 by IHC & 1 & & & & & \\
Ki67 by PCR & $0.345^{*}$ & 1 & & & & \\
CCNB1 & $0.081^{*}$ & $0.285^{*}$ & 1 & & & \\
MYBL2 & $0.104^{*}$ & $0.309^{*}$ & $0.421^{*}$ & 1 & & \\
STK15 & $0.182^{*}$ & $0.552^{*}$ & $0.226^{*}$ & $0.238^{*}$ & 1 & \\
SURV & $0.057^{*}$ & $0.272^{*}$ & $0.137^{*}$ & $0.300^{*}$ & $0.206^{*}$ & 1 \\
\hline
\end{tabular}

* $p$ value less than 0.05

Considering the representative value of the median Ki67 index for distribution, we chose to use the median value to determine low expression and high expression group. Table 3 shows the agreement of high and low Ki67 expression levels by IHC $(\leq 14$, $>14)$ and by RT-PCR $(\leq 5.30,>5.30)$. Ki67 status by IHC was positively but weakly correlated with Ki67 status by RT-PCR.

Table 3. Agreement of High and Low Ki67 Expression Levels by IHC and by RT-PCR

\begin{tabular}{llllll}
\hline & \multicolumn{2}{l}{ Ki67 by RT-PCR, No. } & \multirow{2}{*}{${ }^{\text {K }}$} & X & p value \\
\cline { 2 - 3 } & $\leq 5.30$ & $>5.30$ & & & \\
\hline Ki67 by IHC, No. & $410(62.3 \%)$ & $248(37.7 \%)$ & & & \\
$\leq 14$ & $223(37.1 \%)$ & $378(62.9 \%)$ & & & \\
$>14$ & & & & \\
\hline${ }^{*}$ p value for chi-square test & & & & \\
\hline
\end{tabular}


Table 4. Association of the Clinicopathological Factors and the Concordance between Two Assays' Assessments of Ki67

\begin{tabular}{|c|c|c|c|c|}
\hline & Concordance & Discordance & $x$ & $\mathrm{p}$ value \\
\hline Menopausal status & & & 0.245 & 0621 \\
\hline Pre- Menopausal & $137(32.9 \%)$ & $74(34.9 \%)$ & & \\
\hline Peri- or Post- Menopausal & $279(67.1 \%)$ & $138(65.1 \%)$ & & \\
\hline Pathology, No. (\%) & & & 8.001 & 0.018 \\
\hline IDC & $699(88.7 \%)$ & $393(83.4 \%)$ & & \\
\hline ILC & $31(3.9 \%)$ & $22(4.7 \%)$ & & \\
\hline Others & $58(7.4 \%)$ & $56(11.9 \%)$ & & \\
\hline Grade, No. (\%) & & & 7.661 & 0.022 \\
\hline G1 & $91(13.0 \%)$ & $33(8.4 \%)$ & & \\
\hline G2 & $426(60.8 \%)$ & $268(68.2 \%)$ & & \\
\hline G3 & $184(26.2 \%)$ & $92(23.4 \%)$ & & \\
\hline Tumor Size, No. (\%) & & & 0.655 & 0.418 \\
\hline pT1 & $535(70.7 \%)$ & $315(68.5 \%)$ & & \\
\hline pT2-3 & $222(29.3 \%)$ & $145(31.5 \%)$ & & \\
\hline Nodal status, No. (\%) & & & 0.818 & 0.366 \\
\hline pN0-mic & $678(86.5 \%)$ & $413(88.2 \%)$ & & \\
\hline pN1 & $106(13.5 \%)$ & $55(11.8 \%)$ & & \\
\hline ER status, No. $(\%)$ & & & 2.218 & 0.136 \\
\hline$<50 \%$ & $67(8.5 \%)$ & $52(11.0 \%)$ & & \\
\hline$\geq 50 \%$ & $721(91.5 \%)$ & $419(89.0 \%)$ & & \\
\hline PR status, No. (\%) & & & 0.984 & 0.321 \\
\hline$<20 \%$ & $298(37.8 \%)$ & $165(35.0 \%)$ & & \\
\hline$\geq 20 \%$ & $490(62.2 \%)$ & $306(65.0 \%)$ & & \\
\hline Ki67, No. (\%) & & & 50.054 & $<0.001$ \\
\hline$<10$ & $269(34.2 \%)$ & $126(26.8 \%)$ & & \\
\hline $10-29$ & $287(36.4 \%)$ & $265(56.3 \%)$ & & \\
\hline$\geq 30$ & $232(29.4 \%)$ & $80(17.0 \%)$ & & \\
\hline Recurrence Score, No. (\%) & & & 1.776 & 0.411 \\
\hline$<11$ & $57(7.2 \%)$ & $44(9.3 \%)$ & & \\
\hline $11-25$ & $383(48.6 \%)$ & $224(47.6 \%)$ & & \\
\hline$>25$ & $348(44.2 \%)$ & $203(43.1 \%)$ & & \\
\hline
\end{tabular}

Table 5. Kaplan-Meier Estimates of Disease-free Survival at 3 Years According to Ki67 by IHC and by RT-PCR

\begin{tabular}{|c|c|c|c|c|}
\hline \multirow[t]{2}{*}{ Biomarker } & \multicolumn{2}{|c|}{ 3-year estimated DFS } & \multirow[t]{2}{*}{ LR- $\Delta \chi^{2}$} & \multirow{2}{*}{$\begin{array}{l}\text { Log-rank } \\
\mathrm{p}\end{array}$} \\
\hline & $\begin{array}{l}\text { Low } \\
\text { expression }\end{array}$ & $\begin{array}{l}\text { High } \\
\text { expression }\end{array}$ & & \\
\hline \multicolumn{5}{|l|}{ (1) Training cohort } \\
\hline $\begin{array}{l}\text { Ki67 by RT-PCR }(\leq 5.68 \text { vs } \\
>5.68)\end{array}$ & $96.9 \%$ & $90.5 \%$ & 9.3 & 0.002 \\
\hline \multicolumn{5}{|l|}{ (2) Validation cohort } \\
\hline $\begin{array}{l}\text { Ki67 by RT-PCR ( } \leq 5.68 \text { vs } \\
>5.68)\end{array}$ & $97.0 \%$ & $90.3 \%$ & 8.1 & 0.004 \\
\hline \multicolumn{5}{|l|}{ (3) Whole population } \\
\hline Ki67 by IHC $(\leq 14$ vs $>14)$ & $96.0 \%$ & $92.5 \%$ & 2.5 & 0.1 \\
\hline Ki67 by IHC $(\leq 20$ vs $>20)$ & $96.0 \%$ & $91.7 \%$ & 2.8 & 0.1 \\
\hline Ki67 by IHC $(\leq 30$ vs $>30)$ & $95.8 \%$ & $89.9 \%$ & 5.1 & 0.02 \\
\hline $\begin{array}{l}\text { Ki67 by RT-PCR }(\leq 5.68 \text { vs } \\
>5.68)\end{array}$ & $97.0 \%$ & $90.4 \%$ & 17.4 & $<0.001$ \\
\hline
\end{tabular}

We evaluated the clinical and pathological variables predicting the concordance between two assays' assessments of Ki67 status using chi-square tests (Table 4). None of menopausal status, tumor size, nodal status, ER and PR expression and risk score were related to the concordance between two assays. Only pathology, grade and Ki67 expression by IHC were significantly correlated to the concordance between two assays, and more discordance cases were seen in patients with invasive carcinoma other than IDC and ILC, or patients with Ki67 ranging from 10 to 29 (Table 4).
Prognostic value of Ki67 by IHC and RT-PCR

After a median follow-up of 34.73 months (1.51-113.61 months), there were 84 events: 11 were local-regional recurrence, 13 were contralateral breast cancer, 31 were distant recurrence, 18 were second malignant tumor and 11 were death without recurrence. Using no more than $14 \%$ as cutoff for Ki67 by IHC, the estimated 3-year DFS was $96.0 \%$ in low expression group and $92.5 \%$ in high expression group (Table 5).

Using the X-tile program, the total patient cohort was randomly divided into a matched training and validation set. Table 1 presents the distributions of patient and tumor characteristics in the training and validation cohorts. By use of chi-square tests, we found no significant difference in the classical prognostic factors between the two cohorts, except for PR expression level. What should be pointed out is that intrinsic subtype, which is more representative of tumor biology than PR expression alone, was well balanced between the two cohorts. Ki67 by IHC and by RT-PCR were also properly balanced in the two cohorts. Fig 1 shows training and validation cohorts had similar distribution pattern of Ki67 by RT-PCR.

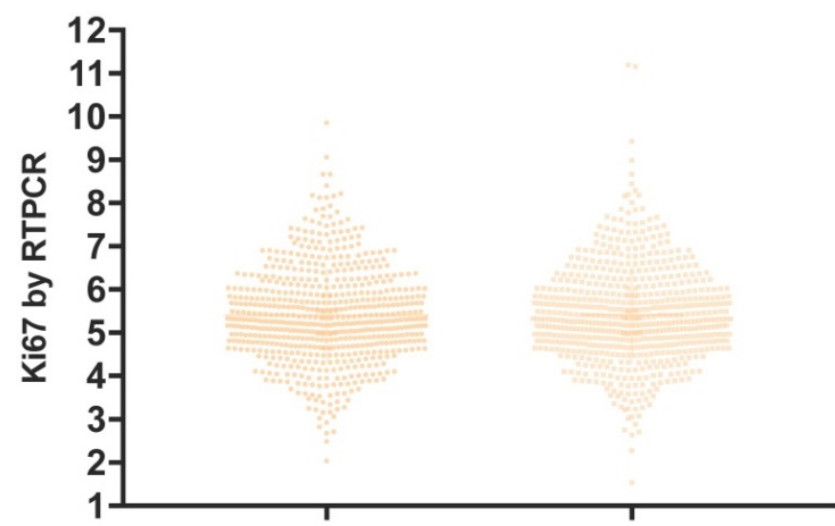

Training cohort Validation cohort

Figure 1. Distribution Pattern of Ki67 Assessed by RT-PCR in Training and Validation Cohorts.

For Ki67 by RT-PCR, 5.68 was determined as the optimal cutoff point using X-tile program in the training cohort. Using Kaplan-Meier estimator, the estimated 3-year DFS was $96.9 \%$ in low expression group and $90.5 \%$ in high expression group (Table 5). The log-rank tests suggested that Ki67 expression by RT-PCR was strongly associated with DFS $\left(\mathrm{LR}-\Delta \chi^{2}=9.3, \mathrm{p}=0.002\right.$, Table 5). Similar results were observed in the validation cohort and whole population (Fig 2). The estimated 3-year DFS was $97.0 \%$ in low expression group of $\mathrm{Ki} 67$ and $90.4 \%$ in high expression group for all patients. The log-rank tests suggested that Ki67 expression level by RT-PCR 
was more strongly associated with disease-free survival than Ki67 expression level by IHC with different cutoff (Table 5).

In univariate analyses of patients in the training cohort (Table 6), none of tumor stage (pT2-3 versus $\mathrm{pT} 1$ ), nodal status ( $\mathrm{pN} 1$ versus $\mathrm{pN} 0-\mathrm{mic}$ ), grade (grade 3 vs. grade 1 or 2 ), Ki67 by IHC (>14 vs $\leq 14 \%$ ), or intrinsic subtype (Luminal B-like vs Luminal A-like) were significant factors for DFS, except for Ki67 by RT-PCR (>5.68 vs $\leq 5.68$ ). High expression of Ki67 by RT-PCR is unfavorable for DFS. Table 6 also shows the results of the univariate analysis of patients in the validation cohort. Tumor stage (pT2-3 versus pT1), Ki67 by IHC (>14 vs $\leq 14 \%$ ), Ki67 by RT-PCR $(>5.68$ vs $\leq 5.68)$, as well as recurrence score ( $>25$ vs $\leq 25)$ were all significant factors for DFS, higher levels of all these factors were unfavorable. In a multivariate analysis including all the markers identified by univariate analysis, none of these markers were independent factors for poorer DFS, although there was a trend for reduced risk with pT1 and Ki67 by RT-PCR $\leq 5.68$ (tumor stage, $p=0.059 ; \mathrm{Ki} 67$ by RT-PCR, $\mathrm{p}=0.052)$. Applying univariate and multivariate analysis to the whole population, tumor stage (pT2-3 versus pT1), intrinsic subtype (Luminal B-like vs Luminal A-like), Ki67 by RT-PCR (>5.68 vs $\leq 5.68)$, as well as recurrence score $(>25$ vs $\leq 25)$ were all significant factors for DFS, and only high expression of Ki67 by RT-PCR - but not intrinsic subtype or recurrence score-was an independent factor for poorer DFS.

Table 6. Univariate and Multivariate Cox Proportional Hazards Analyses for Disease-free Survival in association with Ki67 by RT-PCR in Training and Validation Cohorts and whole population

\begin{tabular}{|c|c|c|c|c|c|}
\hline \multirow[t]{2}{*}{ Variables } & \multirow[t]{2}{*}{ coding } & \multicolumn{2}{|c|}{ Univariate analysis } & \multicolumn{2}{|c|}{ Multivariate analysis } \\
\hline & & $\mathrm{HR}(95 \% \mathrm{CI})$ & $\mathrm{p}$ & $\mathrm{HR}(95 \% \mathrm{CI})$ & $\mathrm{p}$ \\
\hline \multicolumn{6}{|c|}{ (1) Training cohort } \\
\hline $\begin{array}{l}\text { Ki67 by } \\
\text { RT-PCR }\end{array}$ & $>5.68$ vs $\leq 5.68$ & $\begin{array}{l}2.740 \\
(1.396-5.378)\end{array}$ & 0.003 & & \\
\hline \multicolumn{6}{|c|}{ (2) Validation cohort } \\
\hline Tumor stage & $\mathrm{T} 2-3$ vs $\mathrm{T} 1$ & $\begin{array}{l}2.138 \\
(1.189-3.843)\end{array}$ & 0.011 & $\begin{array}{l}1.774 \\
(0.977-3.221)\end{array}$ & 0.059 \\
\hline Ki67 by IHC & $\geq 14 \%$ vs $<14 \%$ & $\begin{array}{l}1.850 \\
(1.019-3.358)\end{array}$ & 0.043 & $\begin{array}{l}1.517 \\
(0.815-2.822)\end{array}$ & 0.189 \\
\hline $\begin{array}{l}\text { Ki67 by } \\
\text { RT-PCR }\end{array}$ & $>5.68$ vs $\leq 5.68$ & $\begin{array}{l}2.370 \\
(1.285-4.371)\end{array}$ & 0.003 & $\begin{array}{l}1.909 \\
(0.995-3.661)\end{array}$ & 0.052 \\
\hline $\begin{array}{l}\text { Recurrence } \\
\text { score }\end{array}$ & $>25$ vs $\leq 25$ & $\begin{array}{l}1.948 \\
(1.070-3.549)\end{array}$ & 0.029 & $\begin{array}{l}1.615 \\
(0.867-3.006)\end{array}$ & 0.131 \\
\hline \multicolumn{6}{|c|}{ (3) Whole population } \\
\hline Tumor stage & $\mathrm{T} 2-3$ vs $\mathrm{T} 1$ & $\begin{array}{l}1.985 \\
(1.285-3.066)\end{array}$ & 0.002 & $\begin{array}{l}1.672 \\
(1.076-2.597)\end{array}$ & 0.022 \\
\hline Nodal status & pN1 vs pN0-mic & $\begin{array}{l}1.432 \\
(0.704-2.913)\end{array}$ & 0.322 & NA & \\
\hline Grade & $\begin{array}{l}\text { Grade III vs Grade } \\
\text { I-II }\end{array}$ & $\begin{array}{l}1.425 \\
(0.862-2.356)\end{array}$ & 0.168 & NA & \\
\hline $\begin{array}{l}\text { Intrinsic } \\
\text { subtype }\end{array}$ & $\begin{array}{l}\text { Luminal B-like vs } \\
\text { Luminal A-like }\end{array}$ & $\begin{array}{l}1.799 \\
(1.056-3.063)\end{array}$ & 0.031 & $\begin{array}{l}1.470 \\
(0.842-2.568)\end{array}$ & 0.176 \\
\hline Ki67 by IHC & $\geq 14 \%$ vs $<14 \%$ & $\begin{array}{l}1.410 \\
(0.917-2.170)\end{array}$ & 0.118 & NA & \\
\hline $\begin{array}{l}\text { Ki67 by } \\
\text { RT-PCR }\end{array}$ & $>5.68$ vs $\leq 5.68$ & $\begin{array}{l}2.540 \\
(1.615-3.997)\end{array}$ & $<0.001$ & $\begin{array}{l}2.179 \\
(1.359-3.494)\end{array}$ & 0.001 \\
\hline $\begin{array}{l}\text { Recurrence } \\
\text { score }\end{array}$ & $>25$ vs $\leq 25$ & $\begin{array}{l}1.670 \\
(1.079-2.584)\end{array}$ & 0.021 & $\begin{array}{l}1.307 \\
(0.832-2.053)\end{array}$ & 0.246 \\
\hline
\end{tabular}

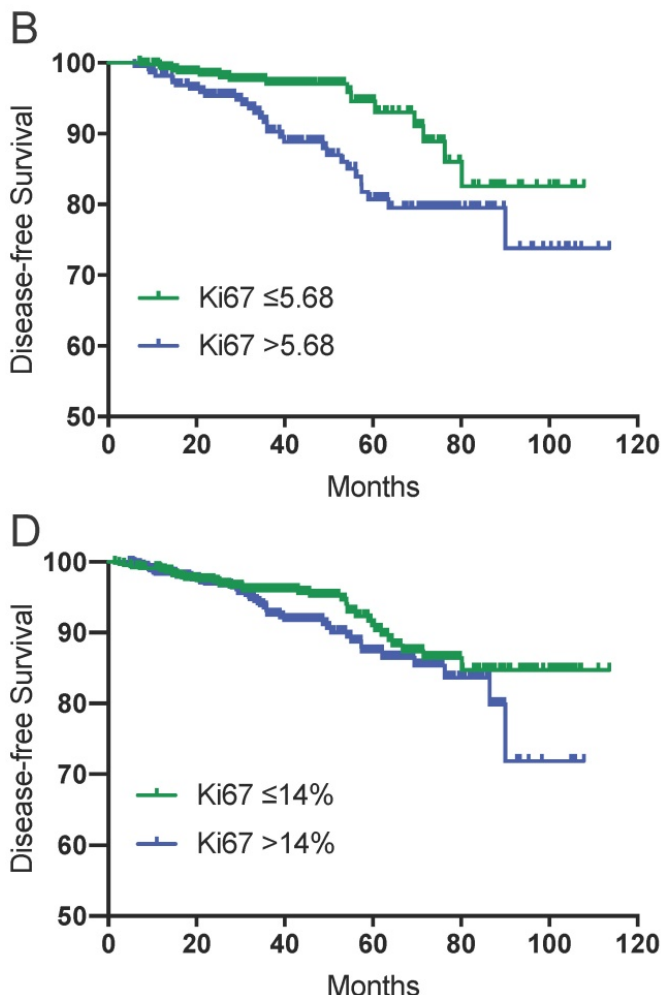

Figure 2. Kaplan-Meier estimates of disease-free survival by Ki67 status. Disease-free survival by RT-PCR assessed Ki67 status in training cohort (A), in validation cohort (B)and in whole population (C); Disease-free survival by IHC assessed Ki67 status in whole population (D). 
To verify the previous results, we also used Basic $\mathrm{R}$ function sample() to divide the study cohort randomly into Cohort 1 and Cohort 2 (Table S1). Using Cohort 1 as training set, 5.69 was determined as the optimal cutoff point by X-tile program for Ki67 by RT-PCR. With either 5.68 or 5.69 as the cutoff point for Ki67 by RT-PCR, the log-rank tests suggested that Ki67 expression by RT-PCR was strongly associated with DFS in the Cohort 1 (Fig S1). While in Cohort 2, there was a strong trend toward worsen DFS with high ki67 by RT-PCR compared to Ki67 $\leq 5.68$, with a $\mathrm{p}$ value of 0.053 (Table S2). In univariate Cox Proportional Hazards Analyses for DFS, Ki67 by RT-PCR was the only significant factor in Cohort 1 $(\mathrm{HR}=3.673$, 95\%CI 1.876-7.193, $\mathrm{p}<0.001)$, but not in Cohort 2 (Table S3).

\section{Discussion}

IHC assessment of Ki67 has been proposed as a potential marker to distinguish luminal $\mathrm{A}$ and luminal $B$ breast cancer and guide adjuvant chemotherapy in HR+/HER2- early breast cancer [6]. Unfortunately, substantial variability in Ki67 scoring was still observed, leading to continuing pursuit for an objective method for Ki67 scoring to achieve high inter-laboratory reproducibility [8, 21, 22]. Here, we present another method for assessment of Ki67 expression in breast cancer, which is based on RT-PCR assay in the setting of 21-gene expression assay.

Although IHC assesses protein expression, while RT-PCR detects mRNA transcription levels, numerous studies have shown a high degree of concordance between the two assays [23-25]. In the study by Badve and colleagues [23], which compared ER and PR status measured by IHC and RT-PCR with 21-gene expression assay in patients from E2197 study, showed high degree of concordance and suggested RT-PCR using the 21-gene expression assay as an alternative method for determining HR status. In the current study, RT-PCR assessment of Ki67 showed a weak concordance with IHC assessment, which could partly be explained by tumor heterogeneity. According to the International Ki67 in Breast Cancer Working Group's standards [16], the IHC assessment of Ki67 was performed in the 'hot-spot' area whereas the PCR assessment is based on a non-specific portion of the tumor. Another possible reason for the weak correlation may be that epigenetic factors lead to the differences between protein expression and mRNA expression.

The association between recurrence risk and Ki67 expression by IHC and RT-PCR was analyzed. 3-year DFS estimates were obtained for the whole cohort, and separately for training and validation cohorts. Unlike the published data $[5,6]$, we did not see a statistically significant association between Ki67 status by IHC and disease outcome in the overall cohort. The absolute difference in 3-year DFS was only 3.5\% between the patients with low Ki67 and high Ki67 expression. The poor performance of Ki67 status by IHC may be the result of insufficient adjustment for clinic-pathological factors and adjuvant treatment. Patients with high Ki67 expression by IHC were more likely to receive adjuvant chemotherapy, which may weaken the prognostic value of Ki67 status by IHC. On the other hand, a statistically significant prognostic value for Ki67 status by RT-PCR was observed in the training cohort. Low Ki67 expression defined by RT-PCR was associated with a decrease in the relative risk of relapse. Although similar results were observed in the whole population, it still needs more evidence to draw a solid conclusion, considering the multivariate analysis in the validation cohort and different results from another randomly divided sub-population.

This study has several limitations. As a retrospective study, the imbalance of tumor characteristics and adjuvant treatment between subpopulation may impact the prognostic analysis. Although Ki67 status by RT-PCR has shown a better prognostic value, further study with two independent cohorts is needed to verify the prognostic and predictive value of RT-PCR assessment of Ki67 and define the optimal cutoff point. And the main weakness in our study is that the median follow-up is too short to observe the differences of survival in Luminal breast cancer. So further follow-up is needed to evaluate the prognostic value of Ki67 expression by two assays.

\section{Conclusion}

In summary, this study demonstrated the potential of Ki67 by RT-PCR as a prognostic marker in HR+/HER2- early breast cancer. Further studies are warranted to verify the prognotic and predictive value of RT-PCR assay measurement of Ki67.

\section{Abbreviations}

RT-PCR: Reverse Transcriptase-Polymerase Chain Reaction; IHC: Immunohistochemistry; RS: Recurrence Score; FFPE: Formalin-Fixed and Paraffin-Embedded; ASCO: American Society of Clinical Oncology; FISH: Fluorescent In Situ Hybridization; STEEP: The Standardized Definitions for Efficacy End Points; DFS: Disease-free Survival; IDC: Invasive Ductal Carcinoma; ILC: Invasive Lobular Carcinoma. 


\section{Supplementary Material}

Supplementary figure and tables. http://www.jcancer.org/v10p1110s1.pdf

\section{Acknowledgements}

This study was funded by grants from the Joint Research Project of the Emerging Cutting-edge Technology of Shanghai Shen-kang Hospital Development Center (Grant Number: SHDC12014103), Medical Guidance Foundation of Shanghai Municipal Science and Technology Commission (15411966400) and Technology Innovation Act Plan of Shanghai Municipal Science and Technology Commission (Grant Number: 14411950200, 14411950201).

\section{Competing Interests}

The authors have declared that no competing interest exists.

\section{References}

1. Gerdes J, Schwab U, Lemke H, Stein H. Production of a mouse monoclonal antibody reactive with a human nuclear antigen associated with cell proliferation. International journal of cancer. 1983; 31: 13-20.

2. Lopez F, Belloc F, Lacombe F, Dumain P, Reiffers J, Bernard P, et al. Modalities of synthesis of Ki67 antigen during the stimulation of lymphocytes. Cytometry. 1991; 12: 42-9.

3. Urruticoechea A, Smith IE, Dowsett M. Proliferation marker Ki-67 in early breast cancer. J Clin Oncol. 2005; 23: 7212-20.

4. Yerushalmi R, Woods R, Ravdin PM, Hayes MM, Gelmon KA. Ki67 in breast cancer: prognostic and predictive potential. The Lancet Oncology. 2010; 11: $174-83$

5. Denkert C, Loibl S, Muller BM, Eidtmann H, Schmitt WD, Eiermann W, et al. Ki67 levels as predictive and prognostic parameters in pretherapeutic breast cancer core biopsies: a translational investigation in the neoadjuvant GeparTrio trial. Ann Oncol. 2013; 24: 2786-93.

6. Cheang MC, Chia SK, Voduc D, Gao D, Leung S, Snider J, et al. Ki67 index, HER2 status, and prognosis of patients with luminal B breast cancer. J Natl Cancer Inst. 2009; 101: 736-50

7. Polley MY, Leung SC, McShane LM, Gao D, Hugh JC, Mastropasqua MG, et al. An international Ki67 reproducibility study. J Natl Cancer Inst. 2013; 105: 1897-906.

8. Curigliano G, Burstein HJ, E PW, Gnant M, Dubsky P, Loibl S, et al. De-escalating and escalating treatments for early-stage breast cancer: the St. Gallen International Expert Consensus Conference on the Primary Therapy of Early Breast Cancer 2017. Ann Oncol. 2017; 28: 1700-12.

9. Andre F, Arnedos M, Goubar A, Ghouadni A, Delaloge S. Ki67-no evidence for its use in node-positive breast cancer. Nature Reviews Clinical Oncology. 2015; 12: 296-301.

10. Allison KH. Ancillary Prognostic and Predictive Testing in Breast Cancer: Focus on Discordant, Unusual, and Borderline Results. Surg Pathol Clin. 2018; 11: $147-76$

11. Paik S, Shak S, Tang G, Kim C, Baker J, Cronin M, et al. A multigene assay to predict recurrence of tamoxifen-treated, node-negative breast cancer. $\mathrm{N}$ Engl J Med. 2004; 351: 2817-26.

12. Sparano JA, Gray RJ, Makower DF, Pritchard KI, Albain KS, Hayes DF, et al. Prospective Validation of a 21-Gene Expression Assay in Breast Cancer. New England Journal of Medicine. 2015; 373: 2005-14

13. Sparano JA, Gray RJ, Makower DF, Pritchard KI, Albain KS, Hayes DF, et al. Adjuvant Chemotherapy Guided by a 21-Gene Expression Assay in Breast Cancer. New England Journal of Medicine. 2018; 379: 111-21.

14. Hammond ME, Hayes DF, Dowsett M, Allred DC, Hagerty KL, Badve S, et al. American Society of Clinical Oncology/College Of American Pathologists guideline recommendations for immunohistochemical testing of estrogen and progesterone receptors in breast cancer. J Clin Oncol. 2010; 28: 2784-95.

15. Wolff AC, Hammond ME, Hicks DG, Dowsett M, McShane LM, Allison KH, et al. Recommendations for human epidermal growth factor receptor 2 testing in breast cancer: American Society of Clinical Oncology/College of American Pathologists clinical practice guideline update. J Clin Oncol. 2013; 31: 3997-4013
16. Dowsett M, Nielsen TO, A'Hern R, Bartlett J, Coombes RC, Cuzick J, et al. Assessment of Ki67 in breast cancer: recommendations from the International Ki67 in Breast Cancer working group. J Natl Cancer Inst. 2011; 103: 1656-64.

17. Camp RL, Dolled-Filhart M, Rimm DL. X-tile: a new bio-informatics tool for biomarker assessment and outcome-based cut-point optimization. Clin Cancer Res. 2004; 10: 7252-9.

18. Mahmoud SM, Paish EC, Powe DG, Macmillan RD, Grainge MJ, Lee AH, et al Tumor-infiltrating CD8+ lymphocytes predict clinical outcome in breast cancer. J Clin Oncol. 2011; 29: 1949-55.

19. Facciabene A, Peng $X$, Hagemann IS, Balint K, Barchetti A, Wang L-P, et al. Tumour hypoxia promotes tolerance and angiogenesis via CCL28 and Treg cells. Nature. 2011; 475: 226-30.

20. Hudis CA, Barlow WE, Costantino JP, Gray RJ, Pritchard KI, Chapman JA, et al. Proposal for standardized definitions for efficacy end points in adjuvant breast cancer trials: the STEEP system. J Clin Oncol. 2007; 25: 2127-32.

21. Denkert C, Budczies J, von Minckwitz G, Wienert S, Loibl S, Klauschen F. Strategies for developing Ki67 as a useful biomarker in breast cancer. Breast. 2015; 24 Suppl 2: S67-72.

22. Koopman T, Buikema HJ, Hollema H, de Bock GH, van der Vegt B. Digital image analysis of Ki67 proliferation index in breast cancer using virtual dual staining on whole tissue sections: clinical validation and inter-platform agreement. Breast Cancer Res Treat. 2018; 169: 33-42.

23. Badve SS, Baehner FL, Gray RP, Childs BH, Maddala T, Liu ML, et al. Estrogen- and progesterone-receptor status in ECOG 2197: comparison of immunohistochemistry by local and central laboratories and quantitative reverse transcription polymerase chain reaction by central laboratory. J Clin Oncol. 2008; 26: 2473-81.

24. Roepman P, Horlings HM, Krijgsman O, Kok M, Bueno-de-Mesquita JM, Bender R, et al. Microarray-based determination of estrogen receptor, progesterone receptor, and HER2 receptor status in breast cancer. Clin Cancer Res. 2009; 15: 7003-11.

25. Viale G, Slaets L, Bogaerts J, Rutgers E, van't Veer L, Piccart-Gebhart MJ, et al. High concordance of protein (by IHC), gene (by FISH; HER2 only), and microarray readout (by TargetPrint) of ER, PgR, and HER2: results from the EORTC 10041/BIG 03-04 MINDACT trial. Ann Oncol. 2014; 25: 816-23. 